Aksaray University
Journal of Science and Engineering
e-ISSN: 2587-1277
http://dergipark.gov.tr/asujse
http://asujse.aksaray.edu.tr

Research Article

\title{
Ultrasonic System Design for Vehicle Detection at Crossroads
}

\author{
Abdulkadir Cildir ${ }^{1}$, Mesud Kahriman ${ }^{1, *}$, Mesut Tigdemir ${ }^{2}$ \\ ${ }^{1}$ Süleyman Demirel University, Engineering Fac., Electrical and Electronics Eng. Isparta, Turkey \\ ${ }^{2}$ Süleyman Demirel University, Engineering Fac., Civil Eng. Isparta, Turkey
}

\begin{abstract}
In this study, an ultrasonic sensor which is thought to be used in traffic signaling is presented. In the ultrasonic sensor circuit, vehicles which have 3 different dimensions have been tried to be detected by using $40 \mathrm{kHz}$ frequency. Vehicle dimensions of about $144 \mathrm{~cm}^{2}, 300 \mathrm{~cm}^{2}$ and 450 $\mathrm{cm}^{2}$ have been used in the study. The vehicles have been placed at an angle of 90 degrees to the ultrasonic sensor at a distances of $30 \mathrm{~cm}, 60 \mathrm{~cm}$ and $90 \mathrm{~cm}$. In addition, the measurements have been tried to determine whether the sensor will be affected by moving the ultrasonic sensor at certain angles. When the dimensions and distances of the vehicles are taken into consideration, it is observed that the voltage values of $2 \mathrm{~V}$ and more have been seen on the oscilloscope.
\end{abstract}

\section{Keywords}

Vehicle Detection, Ultrasound, Crossroad

\footnotetext{
*Corresponding Author: Mesud Kahriman, mesudkahriman@ @du.edu.tr
} 


Aksaray University
Journal of Science and Engineering
e-ISSN: 2587-1277
http://dergipark.gov.tr/asujse
http://asujse.aksaray.edu.tr

Research Article

\title{
Kavşaklarda Araç Tespiti için Ultrasonik Sistem Tasarımı
}

\author{
Abdülkadir Çildir ${ }^{1}$, Mesud Kahriman ${ }^{1, *}$, Mesut Tığgemir ${ }^{2}$ \\ ${ }^{1}$ Süleyman Demirel Üniversitesi, Mühendislik Fak., Elektrik Elektronik Müh. Isparta, TURKIYE \\ ${ }^{2}$ Süleyman Demirel Üniversitesi, Mühendislik Fak. , İnşaat Müh. Isparta, TURKEY
}

-Çevrimiçi Yayın Tarih: 23 Ara 2019

\section{Özet}

$\mathrm{Bu}$ çalışmada, trafik sinyalizasyonunda kullanılması düşünülen ultrasonik sensör gerçekleştirilmesi sunulmuştur. Ultrasonik sensör devresinde $40 \mathrm{kHz}$ frekans kullanılarak 3 farklı boyuta sahip araçlar tespit edilmeye çalışılmıştır. Çalışmada kullanmak için yaklaşık 144 $\mathrm{cm}^{2}, 300 \mathrm{~cm}^{2}, 450 \mathrm{~cm}^{2}$ 'lik araç boyutları tercih edilmiştir. Araçlar ultrasonik sensöre 90 derece açı ile $30 \mathrm{~cm}, 60 \mathrm{~cm}$ ve $90 \mathrm{~cm}$ mesafelerle yerleştirilmiştir. Ayrıca ölçümler, ultrasonik sensör belli açılarla hareket ettirilerek sensörün açılardan etkilenip etkilenmeyeceği de tespit edilmeye çalışılmıştır. Araçların boyutları ve mesafeler dikkate alındığında osiloskopta görülen $2 \mathrm{~V}$ ve üstü gerilim değerlerinde araçların tespit edildiği gözlemlenmiştir.

\section{Anahtar Kelimeler:}

Araç Tespiti, Ultrason, Kavşak

\footnotetext{
*Sorumlu Yazar: Mesud Kahriman, mesudkahriman@sdu.edu.tr
} 


\section{GİRiş}

Günümüzde şehirlerin kalabalıklaşması ve bunun neticesinde otomobil sayısının sürekli artış göstermesiyle, mevcut yol sayısını artırmanın yanında mevcut yol kapasitesini de en iyi şekilde kullanmak zoraki bir hale gelmiştir. İzole sinyalize kavşaklardaki trafik sinyal sürelerinin en uygun bir şekilde ayarlanması kavşaktaki araç sayısını tahmin etmekle birlikte bu kavşaktaki gecikmelerin gerçeğe yakın bir şekilde tahmini ile olmaktadır. Böylece kavşak kapasitesi tam olarak kullanılmış olur. Bununla birlikte kaza sayısının artması, yüksek yakıt maliyetleri, seyahat stresi, çevre problemleri gibi birçok etken bu süreci teşvik etmektedir [1].

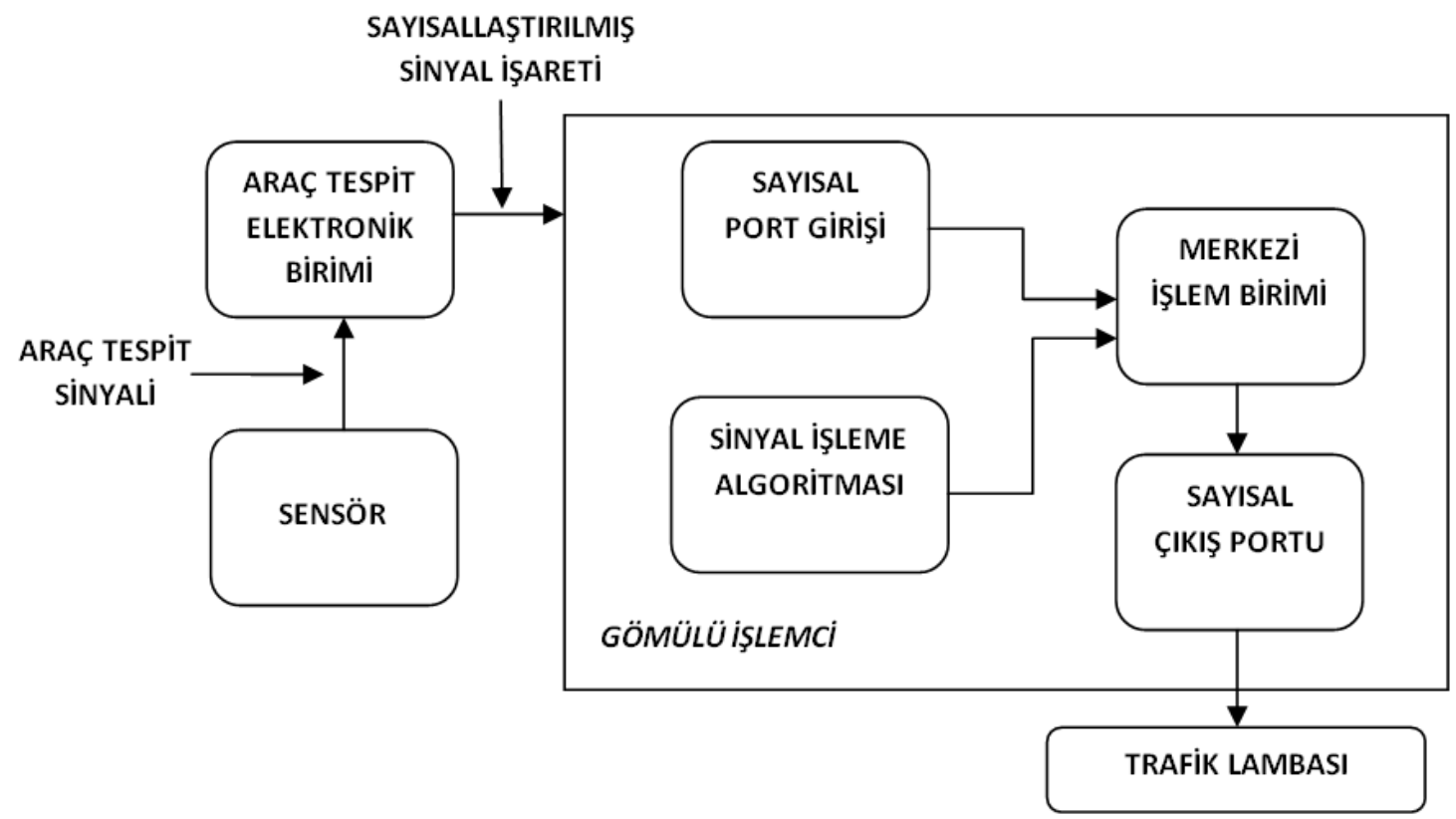

Şekil 1. Kavşak yönetimi blok diyagramı.

Şekil 1'de kavşak yönetimi blok diyagramı verilmiştir. Trafikte kavşak yönetimi bütün bir sistemdir. Burada anlatılacak olan çalışma sadece giriş kısmındaki araç tespit etmek için kullanılan sensör tasarımı ve gerçekleştirilmesidir. Literatürde ve sektörde kullanılan birçok sensör mevcuttur. Bu sensörler; araç tespit teknolojileri başlığı altında incelenebilir.

\section{ARAÇ TESPIT TEKNOLOJILERI}

Araç tespit teknolojilerinde; Yola müdahale edilen (intrusive) Sensörler ve yola müdahale edilmeyen (non-intrusive) sensörler olmak üzere iki farklı yapıda algılayıcılar kullanılabilir.

\subsection{Yola Müdahale Edilen (Intrusive) Sensörler}

i. Endüktif Döngü: Endüktif döngü, yolun yüzeyine monte edilen, döngünün yakınında veya üzerinde hareket ettikçe, döngünün endüktansındaki değişimi ölçen dedektöre denmektedir. 
ii. Pnömatik Yol Tüpü: Pnömatik yol tüpü teknolojisi, belirli bir konfigürasyonda trafik şeritlerine yerleştirilmiş kauçuk tüpleri kullanır. Bir çift tekerlek (bir dingilde) tüpe çarptığında, sıkıştırılmış tüpteki hava basıncı, olayın zamanını not eden bir kayıt cihazını harekete geçirir [2].

iii. Piezoelektrik Sensör: Piezoelektrik sensörler, piezoelektrik malzemeden geçen araçlar tarafından basınç uygulandığında bir potansiyel fark üretir. Piezoelektrik sensörler sayma, hız ölçümü ve araç sınıflandırması için kullanılır [3].

iv. Manyetik Sensör: Manyetik sersörlerin çalışma ilkesi dünyanın manyetik alanına dayanmaktadır. Aracın olduğu yerlerde dünyanın manyetik çizgilerinin yönü değişir ve böylece sensör burada bir cismin olduğunu anlayabilmektedir [4].

İsminden de anlaşılacağı üzere yola müdahale edilen araç teknolojilerinin tercih edilmeme sebeplerinin başlıcaları, sistem kurulumunda ve tamirinde yolda kazı çalışması yapılarak hem yolu bozması hem de trafiği aksatması gösterilebilir.

\subsection{Yola Müdahale Edilmeyen (Non-Intrusive) Sensörler}

i. Video Görüntü Iş̧leme (VIP): Çok fazla kameradan oluşabilmektedir. Görüntünün işlenmesi için mikroişlemci tabanlı bir donanım gerektirir. Ayrıca kamera ile alınan verilerin kaydedilip, analiz edilmesi için bilgisayar ve yazılım gerektirir [5].

ii. Ultrasonik Sensör: İnsan duyulabilir aralığı dışında yüksek frekanslı $(25-40 \mathrm{kHz})$ ses dalgalarını yaygın olarak kullanmaktadır. Temelde mikrodalga radar sistemine benzemektedir. Ses dalgası iletilir ve gelme süresine göre aracın mesafesi hesaplanır. Arka plandaki yüzeyden daha çabuk sinyal geliyorsa bir cismin orada olduğunu tahmin etmektedir [6].

iii. Manyetik Sensör: Manyetik (MAG) sensörler, endüktif döngülere alternatif bir seçenek olarak bulunmuşlardır. $\mathrm{Bu}$ sensörler, hassas ölçüm yaparlar ve hava şartlarına daha dayanıklıdırlar [7]. Maliyetlerinin yüksek olması dezavantajlarıdır.

iv. Mikrodalga Radar: Radar algılama ünitesi, mikrodalga radar dalgalarını yola doğru yansıtır ve herhangi bir dalga geri yansırsa dinler. Ünite yansımaları, temel alarak bir araç olup olmadığını belirleyebilir. Mikrodalga radarın en önemli avantajları arasında hava değişiminden performansının etkilenmemesidir. Radarın karmaşık bir sistem olması ve maliyetinin yüksek olması dezavantajları arasında gösterilebilir. 
A. Cildir et al. (2019). Aksaray University Journal of Science and Engineering, 3(2), 129-138.

Tablo 1. Araç tespit teknolojileri karşılaştırılması.

\begin{tabular}{|l|c|c|c|l|}
\hline Teknoloji & Yola müdahale & Teknik & Maliyet(TL) & Yapılabilirlik \\
\hline $\begin{array}{l}\text { Gerçeklenen Ultrasonik } \\
\text { sensör }\end{array}$ & Yok & Ultrason & 100 & Basit \\
\hline $\begin{array}{l}\text { Ultrasonik Sensör (TC } \\
\text { 30) }\end{array}$ & Yok & Işık & 2000 & Orta[5] \\
\hline $\begin{array}{l}\text { Pnömatik tüp } \\
\text { (RoadPod®VT 5900) }\end{array}$ & Var & Hava & 500 & Orta[5] \\
\hline Piezoelektrik & Var & Elektrik & 750 & Orta[5] \\
\hline Endüktif döngü & Var & Manyetik & 400 & Zor[5] \\
\hline $\begin{array}{l}\text { Manyetik sensör } \\
\text { (HMC2003) }\end{array}$ & Var-Yok & Manyetik & 6000 & Zor[5] \\
\hline Radar (TDN 30) & Yok & Elektromanyetik & 4500 & Çok zor[5] \\
\hline Video (Autoscop solo) & Yok & Kamera & 20000 & Çok zor[5] \\
\hline
\end{tabular}

Tablo 1'de araç tespit teknolojileri bazı yönleriyle birbirleriyle karşılaştırılmıştır. Trafikte yola müdahale edilerek kullanılan teknolojiler trafiğin durdurulması ve yol yapımı çalışmaları gibi dezavantajları olması dolayısıyla arka planda kalmaktadır. Yola müdahale edilmeden kullanılan teknolojilerden ultrasonik sensör, radar ve kamera sistemleri tercihleri daha kullanışı olmaktadır. Yola müdahale gerektirmeyen teknolojilerden ultrasonik sensörler radar ve kameralı sistemlere göre maliyet açısından daha uygundur.

\section{MALZEME VE YÖNTEMLER}

Üzerinde çalışılan ultrasonik sensörün devre şeması aşağıda Şekil 2'de verilmiştir. GIRIS1 ve GIRIS2'ye ultrasonik sensörler bağlanmaktadır ve devre 9V'luk bir DC kaynak ile beslenmektedir.

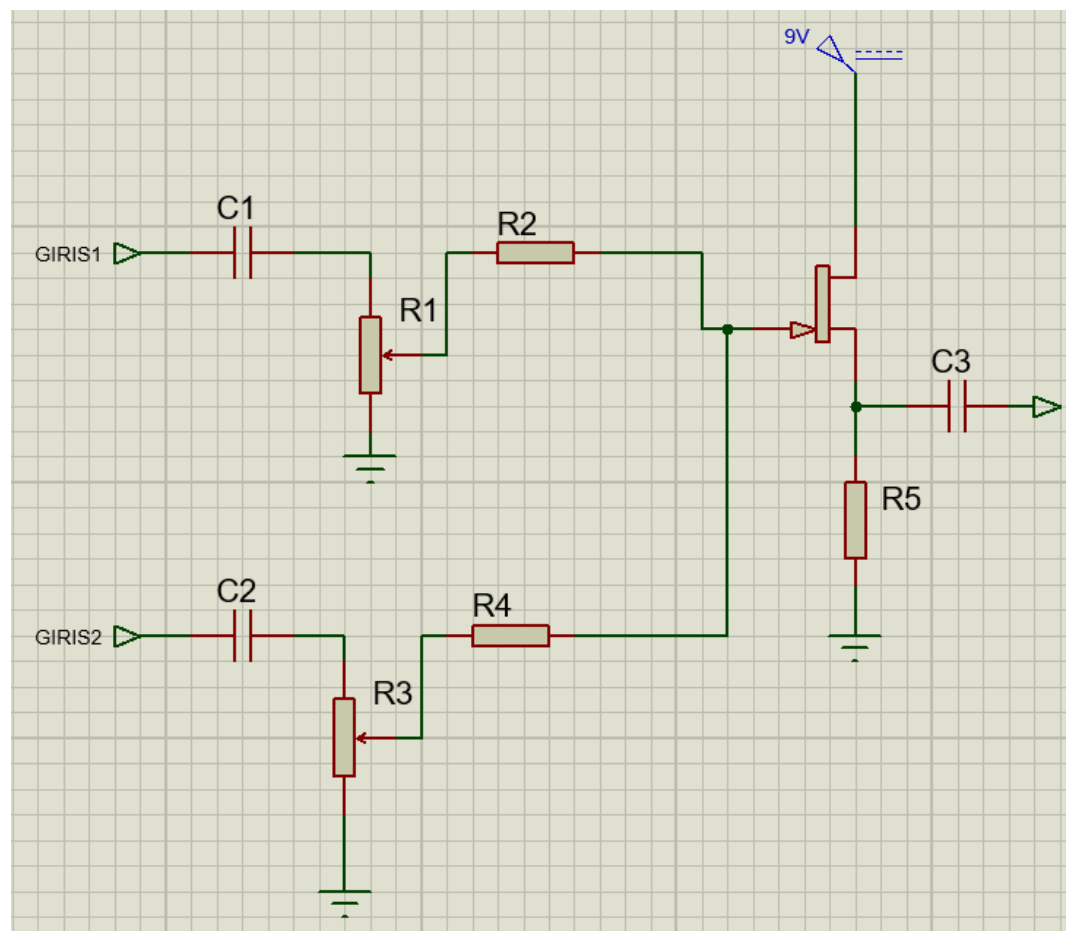

Şekil 2. Gerçeklenen ultrasonik sensör devre şeması 
Şekil 2'de verilen devre için, devre eleman değerleri Tablo 2'de verilmiştir.

Tablo 2 Devre elemen değerleri

\begin{tabular}{|l|l|l|l|l|l|}
\hline Eleman Adı & Değeri & Eleman Adı & Değeri & Eleman Adı & Değeri \\
\hline $\mathrm{C} 1$ & $0.1 \mu \mathrm{F}$ & $\mathrm{R} 1$ & $10 \mathrm{~K} \Omega$ pot & $\mathrm{R} 4$ & $100 \mathrm{~K} \Omega$ pot \\
\hline $\mathrm{C} 2$ & $0.1 \mu \mathrm{F}$ & $\mathrm{R} 2$ & $100 \mathrm{~K} \Omega$ pot & $\mathrm{R} 5$ & $6.8 \mathrm{~K} \Omega$ \\
\hline $\mathrm{C} 3$ & $0.1 \mu \mathrm{F}$ & $\mathrm{R} 3$ & $10 \mathrm{~K} \Omega$ pot & $\mathrm{Q} 1$ & $\mathrm{BF} 245$ \\
\hline
\end{tabular}

Devre şemasında yer alan iki girişten birincisine iletici, diğerine ise alıcı ultrasonik sensör yerleştirilmiştir. $40 \mathrm{kHz}$ frekansta $20 \mathrm{~V}$ gücünde işaret ile beslenilen iletici ultrasonik sensöründen çıkan sinyal işareti, hedef nesneye çarpıp gelerek alıcı sensörden içeri girer ve bu mikser devresinde iki sinyal karşılaştırılarak sensörün önünde cisim olup olmadı̆̆ tespit edilmeye çalışılır. Mikser devremiz, iletilen ve alınan sinyal işaretlerinin farkını alarak hedefte bir nesne olduğu tespit edebilmektedir.

Şekil 2'deki devre şemasına ait gerçeklenmiş devre ise şekil 3'de verilmiştir.

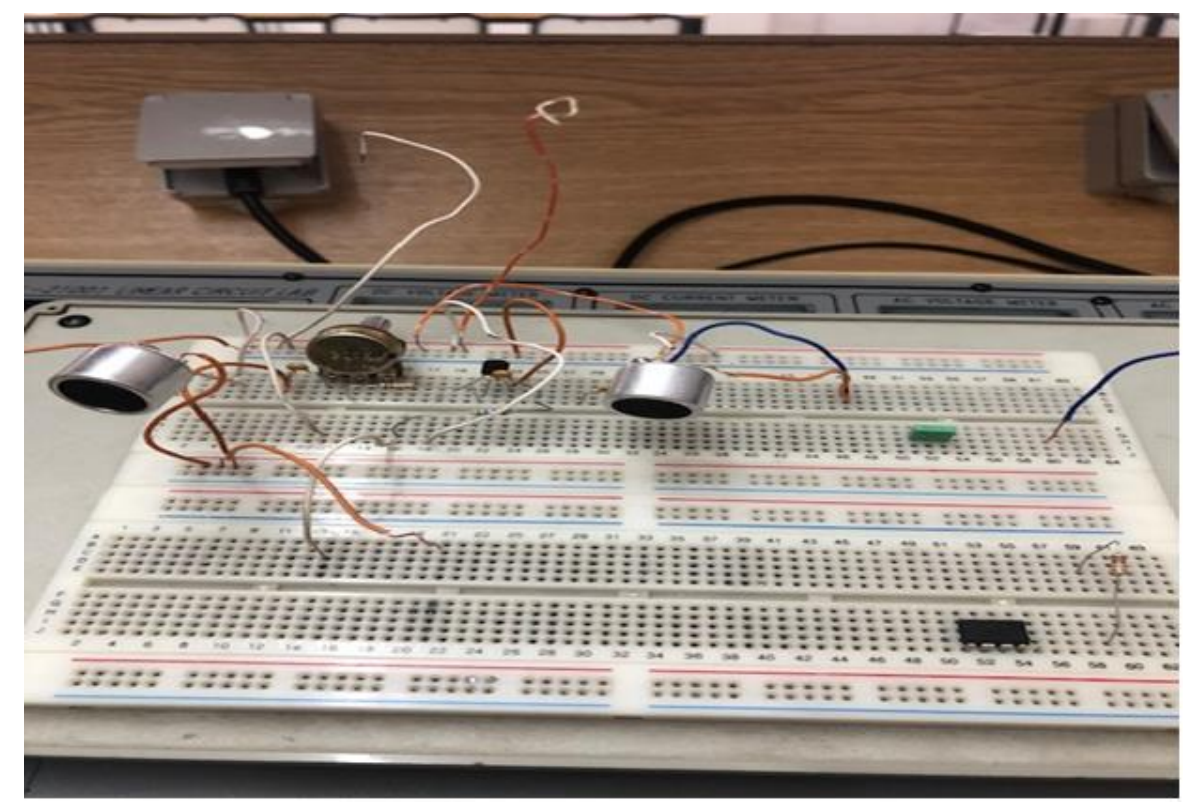

Şekil 3. Gerçeklenmiş ultrasonik sensör.

Ölçümlerde sensörün hata payını minimuma indirgemek için montaj yeri seçimi doğru yapılmalıdır. Sensör ile hedef yüzey arasında mümkün olduğunca az engel bulunmalıdır. Ayrıca sensör ile hedef yüzey arasındaki açı 90 derece seçilmelidir. Şekil 4'de doğru sensör yerleşimi gösterilmiştir. Sensör açık alanda kullanılacak ise montajının yapıldığı yer güneş ışını almamalıdır. Çünkü gelen ışınlarıyla sensör ısınır ve hatalı ölçüme sebep olabilir. 


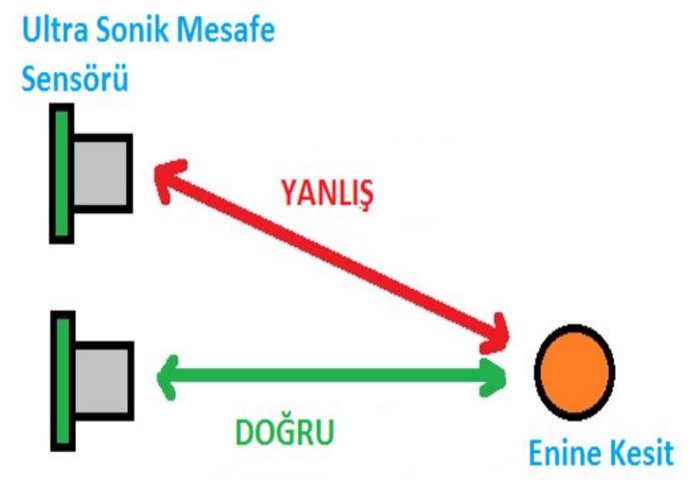

Şekil 4. Ultrasonik sensör yerleşimi gösterimi

\section{BULGULAR VE TARTIŞMA}

Hazırlanan sistemde tespit edilmek üzere 3 farklı boyutta araç seçilmiştir. Kullanılan araç resimleri Şekil 5'te görülmektedir.
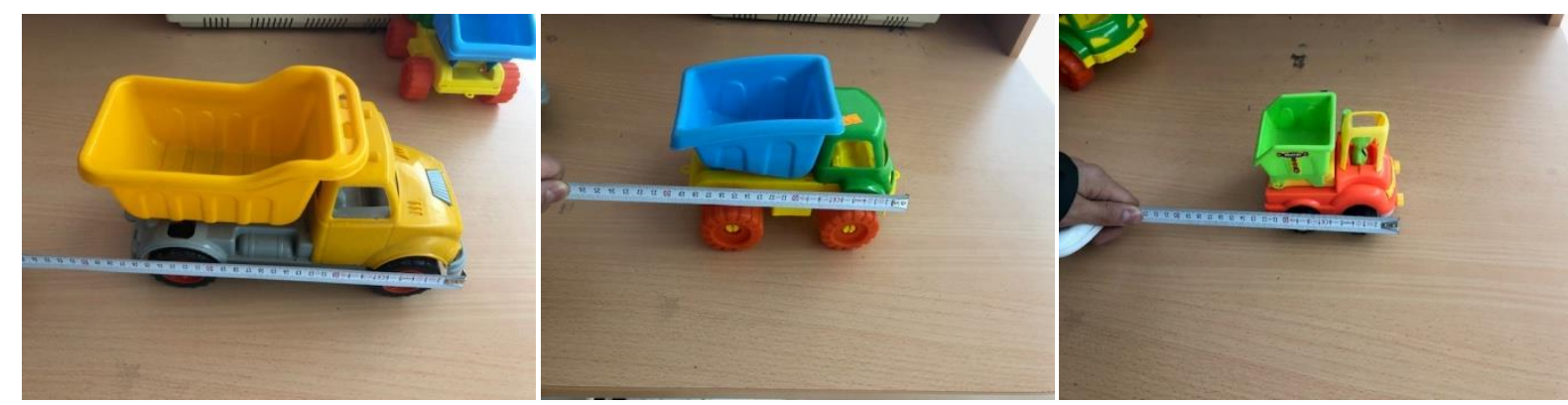

Şekil 5. Deneyde kullanılan araç modelleri.

Ortama araç geldiğinin anlaşılması için, ortamda araç yokken referans ölçüm alınmıştır. Bu ölçüm görüntüsü Şekil 6'da görülmektedir.

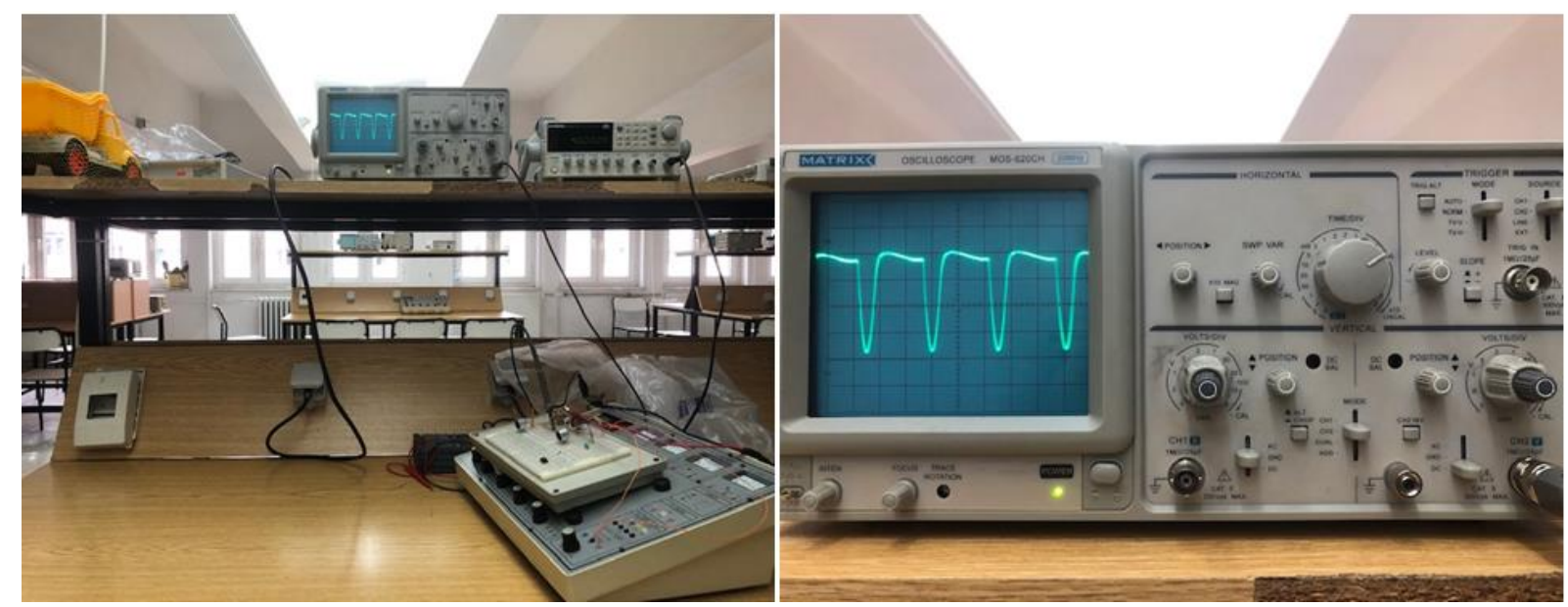

Şekil 6. Menzilde araç yokken deney düzeneği ve osiloskop görüntüsü.

Şekil 6'da sensörün tam karşısında bir araç yoktur. Osiloskopta görülen sinyalin, sensörün çevresindeki cisimlerden ve devre gürültüsünden kaynaklanmaktadır ve bu sinyal referans sinyal olarak kullanılacaktır. 

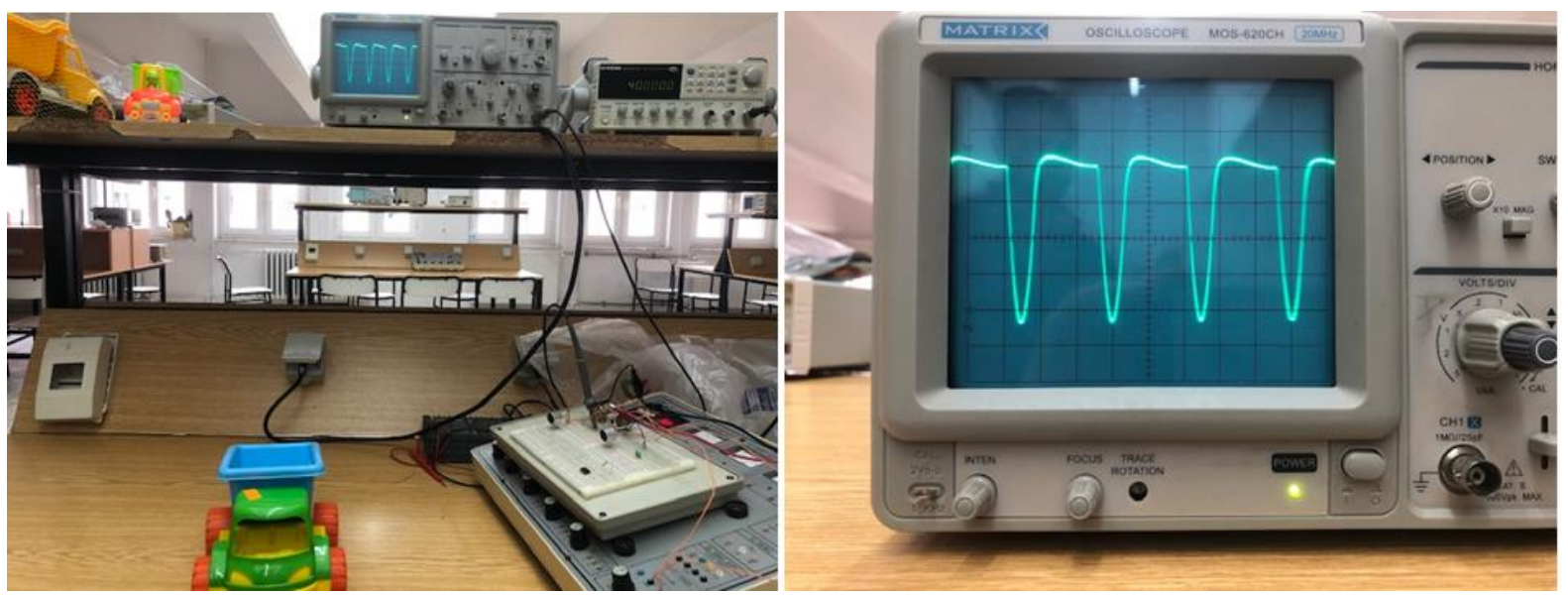

Şekil 7. Menzilde araç varken deney düzeneği ve osiloskop görüntüsü.

Şekil 7'de orta boydaki bir aracın, sensörün $30 \mathrm{~cm}$ karşısına yerleştirilmiş deney düzeneği ve osiloskoptaki sinyal çıktısı verilmiştir. Şekil 6'da sensörün karşısında araç olmadan ve şekil 7'de sensörün karşısındaki araç varken ki osiloskop görüntüsündeki gerilim farkı rahatlıkla görülebilmektedir.

Osiloskop görüntüsündeki dalga şeklinin tepeden tepeye değerleri farklı mesafe ve araç büyüklüklerine kaydedilmiştir. Şekil 8'de hedef aracın boyutlarına göre gerilim-mesafe grafikleri verilmiştir.

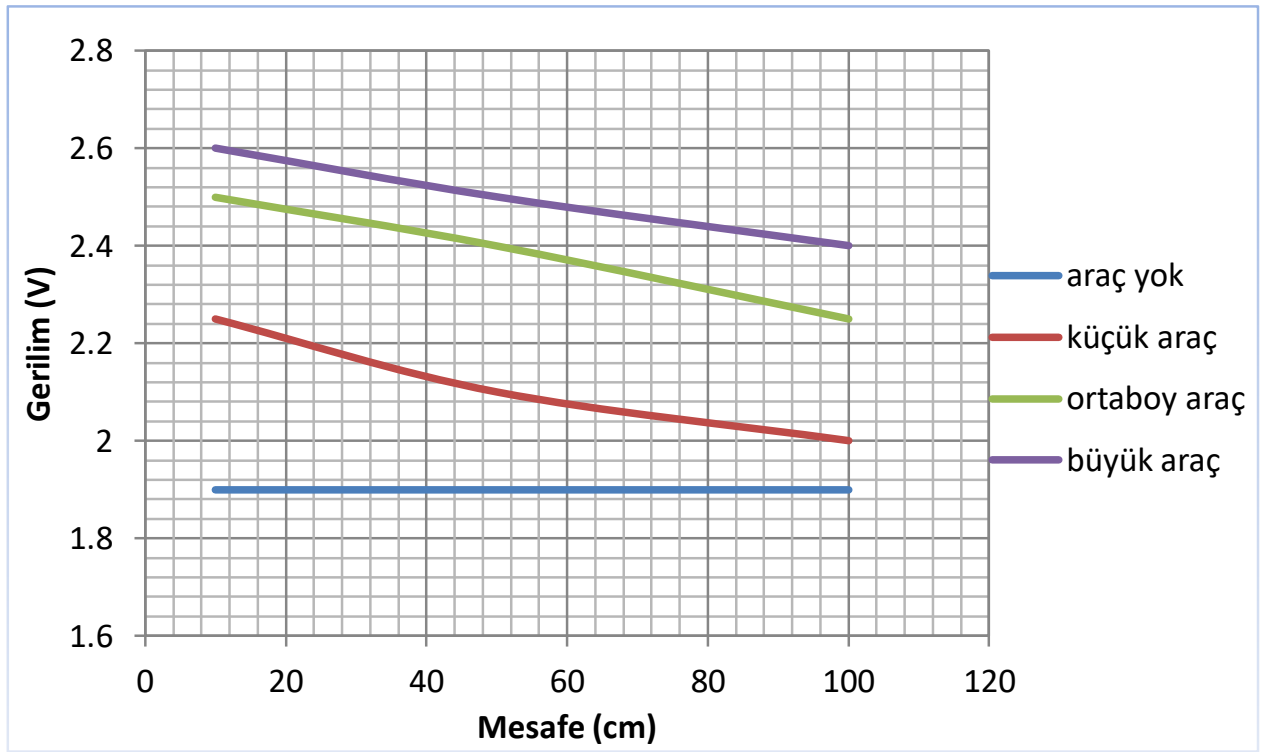

Şekil 8. Hedef nesne gerilim-mesafe grafiği

Aracın, mesafesine ilave olarak görüş açısının da etkisini belirlemek üzere, araçların farklı durumları içinde ölçümler tekrarlanmıştır. Duruş açısı ve araç boyutuna göre tekrarlanmış ölçüm sonuçları Şekil 9'da verilmiştir. 


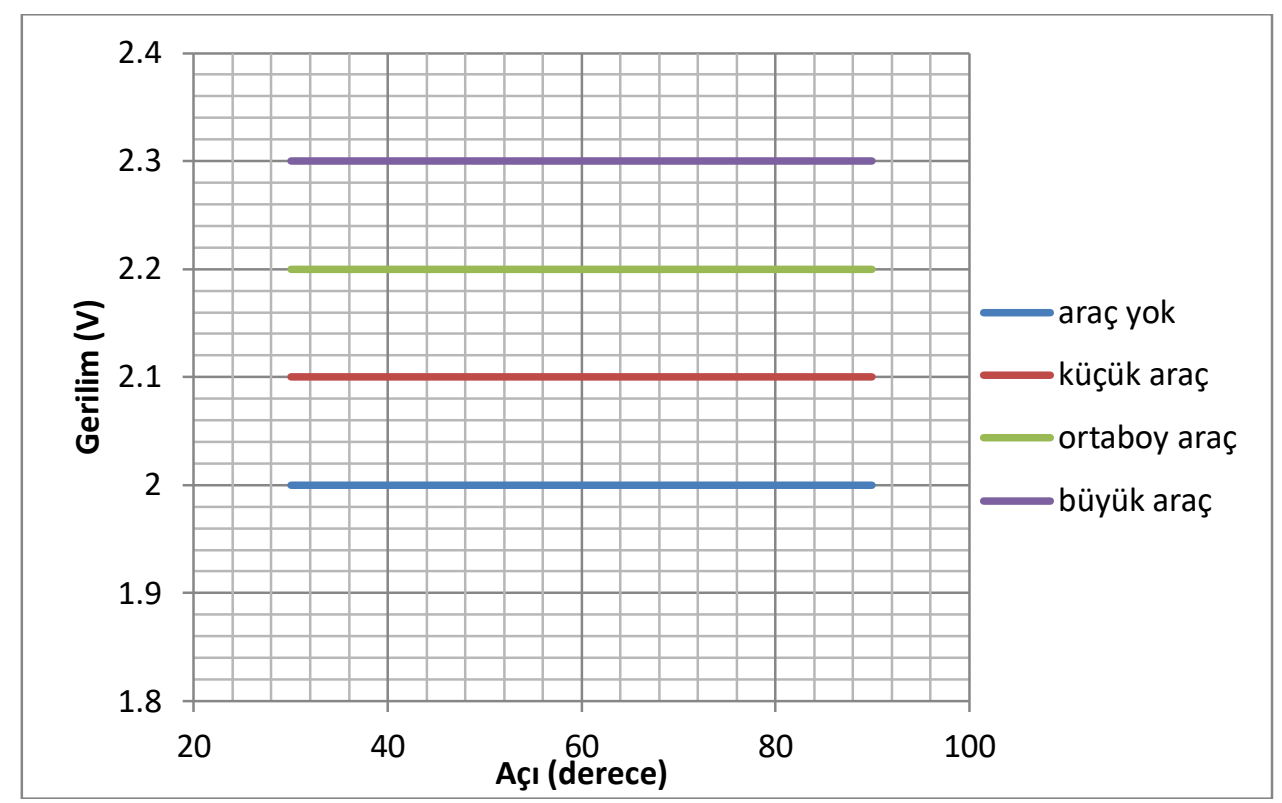

Şekil 9. Hedef nesne gerilim-açı grafiği.

Şekil 8'den de anlaşılacağı üzere yaklaşık olarak 2V gerilim değeri üzerindeki değerlerde ultrasonik sensor bir cisim tespit etmiştir. Mesafe arttıkça ve aracın boyutu küçüldükçe gerilim düşmektedir.

Şekil 9'daki gerilim-açı grafiğinde, sensörün dikey eksene göre konumu açı olarak belirtilmiştir. Hedef nesnenin ise sensöre göre konumu değiştirilmemiş ve her defasında sensöre $90^{0}$ dik bir konumda yerleştirilmiştir. Şekil 9' da gösterildiği gibi ultrasonik sensörün, aracı dik bir şekilde gördüğü sürece kaç derece açı yaptığı önemli değildir. Açı değerine göre gerilimin değişmesi, açı derecesinin değişmesinden ziyade mesafenin değişmesinden kaynaklanmaktadır.

\section{SONUÇLAR}

Gerçekleştirilen çalışmada ultrasonik sensör için belirli mesafelerde belirli araç boyutları için ölçümler yapılmıştır. Ultrasonik sensörler daima araçları 90 derece açılarla görmüş ve önlerinde herhangi bir engel olmadan ölçümler gerçekleştirilmiştir. Yapılan çalışmada mesafe arttıkça osiloskopta görülen gerilim değeri düşmektedir. Ayrıca araç küçüldükçe, gerilim değerimiz de düşmektedir.

Ultrasonik sensör yapımının maliyetinin düşük olması dolayısıyla diğer araç tespit sistemlerine göre de büyük bir avantaja sahiptir. Gelecek çalışmalarda, düşük maliyete sadık kalınarak ultrasonik sensörün görüş mesafesi artırılabilir. Bu sistemin kavşaklara uyumlandırılabilmesi için gürültünün daha yüksek olduğu sahalarda çalışmalar yapılabilir.

Yapılan çalışma bir prototip niteliği taşımaktadır. Yapılan çalışmanın, küçük modellerde çalışıyor olması gerçek büyük sistemlerde çalışabilir olması hakkında fikir vermektedir. İleriye 
A. Cildir et al. (2019). Aksaray University Journal of Science and Engineering, 3(2), 129-138.

dönük olarak; önerilen sistemin park halindeki araçlarda veya otoparklarda test edilmesi için devre tasarımında düzenlemeler yapılabilir. Ayrıca araç tespiti için gerçekleştirilen bu çalışma trafik kavşak yönetimi için bir ön çalışma özelliği taşımaktadır.

\section{KAYNAKLAR}

[1] S. Chiu, Adaptive traffic signal control using fuzzy logic, (Proceedings of the Intelligent Vehicles`92 Symposium, Detroit, MI, USA, 1992), pp. 98-107.

[2] G. Song, C. Olmi, H. Gu, Smart Materials and Structures, 16 (2) (2007) 462-468.

[3] P. McGowen, M. Sanderson, Accuracy of pneumatic road tube counters, (Proceedings of the 2011 Western District Annual Meeting, Anchorage, AK, USA, 2011), pp 4-15.

[4] W. Balid, H. Tafish, H. H. Refai, IEEE Transactions on Intelligent Transportation Systems, 19 (6) (2017) 1784-1794.

[5] L.E.Y. Mimbela, L.A. Klein, Summary of vehicle detection and surveillance technologies used in intelligent transportation systems, (Southwest Technology Development Institute at New Mexico State University, USA, 2000), pp 25-135.

[6] N. Industries, http://novax.com/company/index.html.

[7] D. Schrank and T. Lomax, 2009 urban mobility report, (Texas transportation institute, Texas A\&M University, College Station, Texas, 2009), pp. 21-35 